\title{
8
}
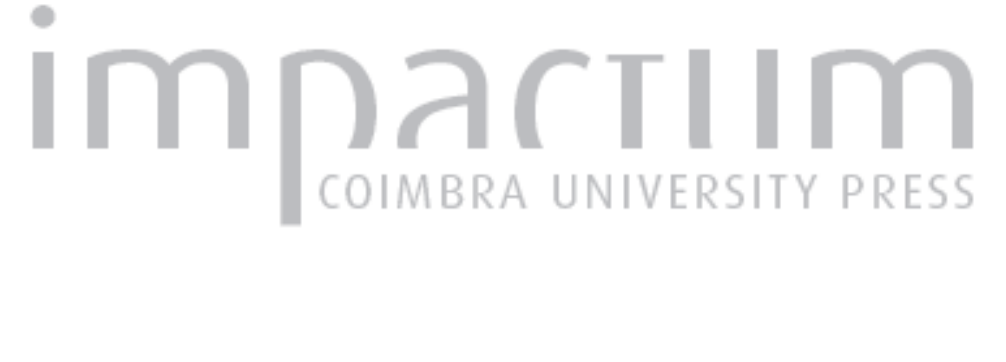

\section{Marcas de oficina em tijolos romanos de Seilium}

Autor(es): $\quad$ Fernandes, Luís da Silva; Ferreira, Rui

Publicado por: Faculdade de Letras da Universidade de Coimbra

URL persistente:

URI:http://hdl.handle.net/10316.2/37674

DOI:

DOI:http://dx.doi.org/10.14195/1647-8657_41_12

Accessed : $\quad$ 26-Apr-2023 13:01:18

A navegação consulta e descarregamento dos títulos inseridos nas Bibliotecas Digitais UC Digitalis, UC Pombalina e UC Impactum, pressupõem a aceitação plena e sem reservas dos Termos e Condições de Uso destas Bibliotecas Digitais, disponíveis em https://digitalis.uc.pt/pt-pt/termos.

Conforme exposto nos referidos Termos e Condições de Uso, o descarregamento de títulos de acesso restrito requer uma licença válida de autorização devendo o utilizador aceder ao(s) documento(s) a partir de um endereço de IP da instituição detentora da supramencionada licença.

Ao utilizador é apenas permitido o descarregamento para uso pessoal, pelo que o emprego do(s) título(s) descarregado(s) para outro fim, designadamente comercial, carece de autorização do respetivo autor ou editor da obra.

Na medida em que todas as obras da UC Digitalis se encontram protegidas pelo Código do Direito de Autor e Direitos Conexos e demais legislação aplicável, toda a cópia, parcial ou total, deste documento, nos casos em que é legalmente admitida, deverá conter ou fazer-se acompanhar por este aviso.

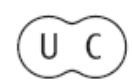




\section{CONIMBRIGA}

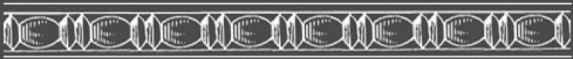

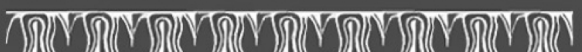
2

INSTITUTO DE ARQUEOLOGIA

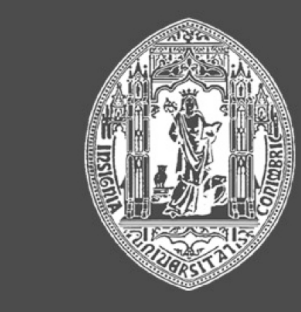

VOLUME XLI - 2002

F A C U L D A E D E LETRAS UNIVERSIDADE DE COIMBRA 
Luís Da Silva Fernandes

Assistente da Faculdade de Letras da Universidade Católica Portuguesa (Viseu)

RUI FERREIRA

Técnico Auxiliar de Museografia do Convento de Cristo (Tomar)

\section{MARCAS DE OFICINA EM TIJOLOS ROMANOS DE SEILIVM}

"Conimbriga" XLI (2002) p. 257-267

RESUMO: Estuda-se uma marca inédita (RPS), gravada antes da cozedura em dois lateres da ciuitas de Seilium (Lusitânia), depositados no Convento de Cristo (Tomar).

Propõe-se uma interpretação da referida marca, sugerindo que esta documenta a produção municipal de cerâmica de construção em Seilium, no século I d. C.

RÉSUMÉ: Étude de la marque inédite RPS, gravée en creux, avant cuisson, sur deux lateres de la ciuitas de Seilium (Lusitanie), déposés au Convento de Cristo (Tomar).

On propose une interprétation de cette marque, en suggérant qu'elle documente la production municipale de céramique de construction, au $\mathrm{I}^{\mathrm{e}}$ siècle ap. J.-C. 
(Página deixada propositadamente em branco) 


\section{MARCAS DE OFICINA EM TIJOLOS ROMANOS DE SEILIVM}

As primeiras intervenções arqueológicas no concelho de Tomar, realizadas entre finais do século XIX e meados deste século, exumaram vestígios de dois sítios romanos: em Cardais, lugar situado a cerca de $2 \mathrm{~km}$ de Tomar, na margem esquerda do rio Nabão (Marmelais de Baixo, freguesia de Santa Maria dos Olivais), foi posta a descoberto a pars urbana de uma uilla, posteriormente destruída, apesar da relevância das estruturas e do espólio encontrado (cf. AlARCÃO, 1992: 13-14; FERreira e Ponte, 1992: 55-56) ${ }^{1}$; em Tomar, no Cerrado de João de Couto (freguesia de Santa Maria dos Olivais), surgiram os primeiros vestígios do municipium de Seilium ${ }^{2}$.

Parte considerável do espólio recolhido nestas intervenções foi depositada no Convento de Cristo (Tomar), integrando a colecção da União dos Amigos dos Monumentos da Ordem de Cristo (= UAMOC), associação fundada em 15 de Maio de 1918 (VEloso, 1992: 153). A UAMOC, que exerceu uma prolífera acção em prol da recuperação e preservação do Convento de Cristo, promoveu a aquisição estatal da Casa do Capítulo Incompleta, parte integrante do referido monumento,

1 Inicialmente, os achados arqueológicos de Cardais foram erradamente interpretados como vestígios de uma urbe romana, identificada com a lendária Nabância (SIlVA, 1883: 152-154; cf. AlARCÃO, 1988c: 59-66); a cerca de 800 metros da uilla foi detectado um forno de cerâmica, próximo de um ribeiro (vide AlARCÃo, 1988b: 112, n. ${ }^{\circ}$ 5/27).

2 Embora não tenha sido dado relevo aos resultados das sondagens do ano de 1952 (vide SILVA, 1951: 51), na década de 80 as pesquisas arqueológicas de Salete da Ponte, juntamente com a equipa do Centro de Estudos e Protecção do Património da Região de Tomar, revelaram, na mesma zona, as estruturas do Forum de Seilium (PonTe, 1985: 18-19; PonTe, 1993: 447-448). O estatuto municipal de Seilium está documentado por uma dedicatória ao Génio do Município (AE 1993, n. ${ }^{\circ}$ 881; finais do século I d. C.), reutilizada na torre de menagem do Castelo dos Templários; relativamente a essa dedicatória, vide FERNANDES, 1997: 158-162, com mais bibliografia. 
onde instalou o Museu da UAMOC, no ano de 1923 (Veloso, 1992: 153). Aquela associação depositou aí parte do espólio oriundo das escavações de Cardais, ao qual vieram juntar-se os materiais romanos encontrados no Cerrado de João de Couto (SILVA, 1951: 51; BATATA, 1997: 18). Actualmente, é difícil determinar com exactidão a proveniência de todas as peças arqueológicas pertencentes a essa colecção tomarense (vide FERREIRA e PONTE, 1992: 57); de qualquer modo, as cerâmicas romanas desta colecção são oriundas dos dois locais acima referidos.

No decurso de uma pesquisa relativa a materiais cerâmicos romanos integrados na referida colecção ${ }^{3}$, lográmos identificar marcas de oficina em dois lateres, sem indicação de proveniência:

1. Tijolo fragmentado, sem rebordo, com as seguintes dimensões: 21 x 20,5 x 5 / 6,5 cm; não tem campo epigráfico delimitado.

$$
\mathrm{R} \cdot \mathrm{P} \cdot \mathrm{S}
$$

Altura das letras: $\mathrm{R}=6,5 ; \mathrm{P}=5,7 ; \mathrm{S}=8 \mathrm{~cm}$.

Grafito feito antes da cozedura. A incisão, profunda, foi realizada com a ajuda dum instrumento duro. A escrita, de tipo actuário, é característica do século I d. C. ${ }^{4}$ : o R com pança aberta; sobretudo o P, cuja pança é substituída por uma haste oblíqua, inclinada para a direita; $\mathrm{S}$ alongado.

2. Tijolo quadrangular, sem rebordo, com as seguintes dimensões: 20,5 x 20,5 x 6,8 cm; não tem campo epigráfico delimitado.

R P S

Altura das letras: $\mathrm{R}=17,5 ; \mathrm{P}=13 ; \mathrm{S}=10,5 \mathrm{~cm}$.

A incisão é larga e pouco profunda; foi feita com o dedo. Letras desenhadas com regularidade, datáveis do século I d. C. 5. R e P com pança fechada; S simétrico, traçado com elegância.

3 Um dos signatários deste artigo (L. S. F.) concluiu já o estudo das marcas de oleiro patentes em pesos de tear da citada colecção, a publicar no Ficheiro Epigráfico; o referido estudo está integrado no projecto de investigação "Sellium e o seu território", coordenado pela Doutora Salete da Ponte.

4 Cf. FC II 372, pl. XXVIII; MARIChal, 1988: 37-39, P4, R1, S4.

5 Cf. FC II 442, pl. XXXIII; MARICHAL, 1988: 36, P2. 
O primeiro exemplar ostenta puncta distinguentes após cada uma das letras, pelo que estamos perante três siglas; a segunda inscrição não apresenta puncta mas as letras estão claramente separadas. Assim, tendo em conta que a menção da $R($ es $) P($ ublica $)$ é habitualmente representada pelas siglas R. P. ${ }^{6}$ e que as duas peças são oriundas do território de Seilium, propomos a seguinte interpretação7:

\section{$\mathrm{R}($ es) $\mathrm{P}$ (ublica) $\mathrm{S}$ (eiliensis)}

\section{A República Seiliense.}

As duas marcas documentariam pois a produção municipal de cerâmica de construção ${ }^{8}$. Note-se que, em Conimbriga, existe um paralelo para esta marca (vide FC II, n. ${ }^{\circ}$ 297, pl. XXIII): um tijolo (incompleto e sem rebordo) encontrado nas escavações mais antigas apresenta uma marca impressa, em relevo (RPC), com a interpretação $R(e s)$ $P($ ublica $) C$ (onimbrigensis $)^{9}$. No território português conhece-se apenas mais um documento relacionável com a produção municipal de cerâmica de construção: a marca AFL, registada em escrita actuária, numa tegula do povoado mineiro de Três Minas (Vila Pouca de Aguiar), cujo desdobramento mais provável será A(quae) FL(auiae) (vide WAHL, 1988: 234-235; AlARCÃo, 1990: 415) ${ }^{10}$.

6 Vide, por exemplo, uma inscrição de Santiago da Guarda (Ansião), no limite do território de Seilium, reexaminada por A. Nunes Monteiro e José Encarnação (1993-1994: 305-311): Ve(ctigale) R(ei) P(ublicae) M(unicipii) uicini.

7 Em alternativa, face a alguns paralelos do mundo romano (ILS 8667b, por exemplo), poderiamos admitir o seguinte desdobramento das siglas: $\mathrm{R}($ ei $) \mathrm{P}($ ublicae) $\mathrm{S}($ eiliensium).

8 A possibilidade de ambas as marcas serem oriundas da área de Cardais e não de Seilium, tendo em conta a ausência de registo de proveniência, não afecta a interpretação das siglas e do seu significado, já que, na época romana, era habitual (e desejável) a localização das instalações de fabrico de cerâmica de construção fora da cidade e nas proximidades dos barreiros (cf. Tsiolis, 1997: 12O, nota 5).

9 O facto de as marcas seilienses apresentarem escrita actuária e não serem impressas não significa necessariamente que não identifiquem o fabricante dos lateres; tal facto poderá dever-se simplesmente a um curto período de fabrico, que não justificasse a estampilhagem das peças produzidas, por exemplo. Por outro lado, é possível que os dois lateres não tenham sido produzidos numa oficina municipal, mas sim numa oficina particular, à qual a ordo decurionum de Seilium teria feito a encomenda (vide ÉTIENNE e MAYET, 1984: 164, com um possível paralelo).

10 Embora existam mais informações sobre a produção privada de cerâmica de construção no território português, quer a nível de fornos, quer a nível de marcas em 
Esta escassez de dados sente-se igualmente no território espanhol. $\mathrm{Na}$ Tarraconense, Christian Rico (1993: 64) não registou nenhuma intervenção da administração local na produção de cerâmica de construção ${ }^{11}$. Na Bética, ocorre apenas a marca CARTEIA, impressa em tijolos oriundos das ruínas de Carteia (RóldAN GómEZ, 1993: 339). Na área espanhola da Lusitânia, as siglas do nome da capital provincial - C(olonia) I(ulia) A(ugusta) E(merita) — estão documentadas em marcas cerâmicas oriundas de diversos locais de Mérida (LE RouX, 1982: 69, nota 281; ETIENNE e MAYET, 1984: 161-168): C • I • A • E • F •; em peças de terra sigillata hispânica proveniente de Tritium Magallum $^{12}$; C. I. A. E. em duas telhas de rebordo ${ }^{13}$; C I A E • AN C • CC • $\mathrm{V}$, num cano de chumbo ${ }^{14}$. A siglas C. I. A. E. estão igualmente presentes numa inscrição votiva de Mérida ${ }^{15}$.

A produção municipal de cerâmica de construção está documentada desde o século II a. C., em cidades do Sul de Itália e da Sicília (BELTRÁN LlORIS, 1994: 197). Em épocas posteriores, regista-se em várias regiões do mundo romano, como atestam as seguintes marcas: Rei Pub(l)icae / Tusculanor(um), em telhas de Tusculum (ILS 8667b); $R($ ei) $P$ (ublicae) G(leuensium), em tijolos de Gloucester (BRODRIBB, 1987: 118; Beltrán Lloris, 1994: 197, nota 212); C(olonia) C(opia)

tégulas e em tijolos (vide ALARCÃo, 1988 a: 137-140), continua a faltar um estudo de conjunto que procure esclarecer questões como a tipologia dos fornos relacionados com esta indústria, a identificação de oficinas regionais e respectivos mercados, grau de literacia dos trabalhadores, peso da intervenção do elemento feminino, bem como a análise onomástica e social dos proprietários e trabalhadores, em relação com a epigrafia local (cf. ALARCÃo, 1990: 427; FC II: 217-219; FERNANDES, 1998-99: 181-182).

11 Christian Rico (1993: 64 e nota 49) não teve em conta o achado de Três Minas.

12 Étienne e Mayet, 1984: 161-164 - C(oloniae). I(uliae). A(ugustae). E(meritae). F(iglinae?); datável entre meados do século I d. C. e meados do século II d. C. 13 Étienne e MaYeT, 1984: 165 - C(oloniae) I(uliae) A(ugustae) E(meritae); atribuídas ao século II d. C.

14 Étienne e MAYet, 1984: 167 - C(oloniae) I(uliae) A(ugustae) E(meritae). $A N($ no) C(oloniae). CC (ducentum). V (quinque); datada de 180 d. C. Numa canalização de chumbo de Évora, foi encontrada a marca LIB(eralitas) IVL(ia), documentando a primeira designação oficial do município de Ebora (ENCARNAÇão, 1990: 234 e 235, figura 1). Em Itálica, encontrou-se um cano de chumbo com a marca C(oloniae). A(eliae). A(ugustae). I(talicae) (ÉTIENNE e MAYET, 1984: 168 e nota 30).

15 Étienne e MAYet, 1984: 168 - G(enio). C(oloniae) I(uliae). A(ugustae). E(meritae) / C(aius) Antistius / C(aii) Lib(ertus) Iucundus / palm(a). ex p(ondo) (hedera) II (duarum unciarum) / u(otum). s(oluit). l(ibens) a(nimo). 
C(laudia) A(ugusta) L(ugdunum), em tijolos de Lyon (ETIENNE e MAYET, 1984: 165 e 167$)^{16}$.

Além dos exemplos acima citados, que reforçam consideravelmente a interpretação proposta para as duas marcas seilienses, a associação do título res publica com o nome da cidade, em marcas oficinais (por extenso ou em sigla), ocorre também em canos de chumbo, como demonstram dois achados de Canusium: ILS 8703a $-r(e i)$. p (ublicae). C(anusinorum). cur(ante). P(ublio). Graec(idio). Firmo.; ILS 8703b - rei publicae municipum Canusinorum / sub cura L. Eggi Marulli.

A expressão res publica é habitualmente utilizada para designar uma comunidade com certa autonomia para gerir os assuntos colectivos, bem como um tesouro público e bens próprios, independentemente do seu estatuto jurídico (vide LE ROUX, 1990: 39-40; GONZÁLEZ RODRÍGUEZ, 1994: 685; LE RouX, 1994: 167-168). Está epigraficamente atestada desde meados do século I d. C. e generaliza-se na época dos Severos, ocorrendo ainda no reinado de Constantino (cf. DARDAINE, 1993: 49) ${ }^{17}$.

A produção municipal de cerâmica de construção em Seilium, no século I d. C., insere-se certamente no quadro de actuação da administração local relativamente à construção ou reparação de edifícios, entre outras obras públicas (estradas, canais, cloacas...), conforme estipula a lex Irnitana (lex Irnit. 63, 79 e 82; cf. ABASCAL e EsPINOSA, 1989: 171), bem como a lex Ursonensis (cf. ABASCAL e ESPINOSA, 1989: 177). Atendendo à datação das marcas, é possível que tal produção esteja relacionada com o programa de construção do centro cívico de Seilium, ou, em alternativa, com a renovação urbanística eventualmente ocor-

16 Note-se ainda a produção de cerâmica de construção em Londres, expressa pela marca PP. BR. LON (= Prouinciae Brittania Londini), bem como a produção municipal de ânforas em cidades africanas (BELTRÁN LLORIS, 1994: 197 e notas 212-213; cf. BRODRIBB, 1987: 118).

17 Na epigrafia do conuentus Scallabitanus registam-se mais 4 ocorrências da expressão res publica, precisamente em territórios vizinhos de Seilium, embora apresentem uma datação mais tardia: Aeminium (CIL II S 5239: [b(onum) e]t augmentum [re] i pub(licae) nato; 305-306 d. C.), Collippo (ERC III: [om]nibus ho[n]oribus in R(e) [P(ublica) C]ollippone[nsi func]to; séc. III d. C. ?), Conimbriga (FC II 297: R(es) $P($ ublica) C(onimbrigensis?); séc. III-IV d. C.) e em Santiago da Guarda, zona situada na fronteira entre Seilium e Conimbriga (ENCARNAÇão e MonTEIRO, 1993-94: ue(ctigale) R(ei) P(ublicae) m(unicipii) uicini; séc. III d. C.). Relativamente ao conuentus Pacensis, vide ENCARNAÇão, 1984a: 9-11 e IRCP 3, 4, 75, 186, 239. 
rida após a promoção do oppidum seiliense a municipium, durante a época flaviana (vide ALARCÃO, 1992: 11; MANTAS, 1992: 33); esta última hipótese é sugerida pela cronologia da dedicatória ao Génio municipal, bem como pela cronologia da utilização epigráfica da expressão res publica $^{18}$.

Tendo em conta a raridade das marcas cerâmicas de fabrico municipal no território peninsular, os dois testemunhos seilienses assumem especial relevo, sugerindo (à luz dos documentos conhecidos) uma maior intervenção dos poderes municipais da Lusitânia na produção de cerâmica, relativamente ao resto da Hispania. Quanto ao municipium de Seilium, a marca RPS traz novos dados à história económica local, demonstrando a existência de produção municipal de cerâmica de construção, numa ciuitas onde as diversas escavações arqueológicas e achados ocasionais começam a desvendar informações sobre a produção cerâmica de carácter privado ${ }^{19}$.

\section{SIGLAS UTILIZADAS}

$\mathrm{AE}=$ L' Année Épigraphique, Paris (indica-se o ano e o número da inscrição). $\mathrm{CIL}=$ Corpus Inscriptionum Latinarum (indica-se o volume e o número da inscrição). $\mathrm{ERC}=$ ver Brandão, 1972 (indica-se o número da inscrição).

FC II — ver Étienne e Fabre, 1976 (indica-se o número da inscrição).

ILS — ver Dessau, 1974 (indica-se o número da inscrição).

IRCP — ver Encarnação, 1984b (indica-se o número da inscrição).

lex Irnit. — ver Ors e Ors, 1988 (indica-se o número da rubrica).

\section{BIBLIOGRAFIA}

Abascal, Juan Manuel; EsPinosa, Urbano (1989): La ciudad hispano-romana. Privilegio y poder, Logroño.

AlarCão, Jorge de (1988a): O Domínio Romano em Portugal, Lisboa.

18 Segundo Dardaine (1993: 57-58), na Bética, a utilização epigráfica da expressão respublica está atestada desde a época flaviana; refira-se que, fora da Hispania, as suas primeiras ocorrências epigráficas datam do reinado de Nero, em Itália (DARDAINE, 1993: 49, nota 10) e em África (GASCOU, 1979: 387).

19 A esse propósito, vide, por exemplo, PONTE, 1988: 89-91 (cerâmica de construção); Ponte, 1993: 452 (cerâmica de construção); PONTE e FERnANDES, 1993: 176 (fornos); PonTe, 1996: 199 (forno de Assentiz). 
Alarcão, Jorge de (1988b): Roman Portugal, vol. II (fasc. II: Coimbra \& Lisboa), Warminster.

Alarcão, Jorge de (1988c): «Nabância e Concórdia», Anais da Real Sociedade Arqueológica Lusitana, 2. série, vol. II, Lisboa, 59-66.

AlARCão, Jorge (1990): «A produção e a circulação de produtos», in Nova História de Portugal, vol. I (Portugal das origens à romanização), Lisboa, 409-441.

Alarcão, Jorge de (1992): «O território de Sellium», O Espaço Rural na Lusitânia. Tomar e o Seu Território (Actas do Seminário, Tomar, 17 a 19 de Março, 1989), Tomar, 9-23.

Batata, Carlos (1997): As Origens de Tomar - Carta Arqueológica do Concelho, Tomar.

BELTRÁN Lloris, Miguel (1994): «Artistas y artesanos en la antiguedad clásica. Los ceramistas y alfareros en Roma», in Artistas y Artesanos en la Antiguedad Clásica (Cuadernos Emeritenses - 8), Mérida, 159-213.

BRANDÃo, Domingos de Pinho (1972): «Epigrafia romana coliponense», Conimbriga, 11, 41-192.

BRODRIDD, Gerald (1987): Roman Brick and Tile, Gloucester.

DARDAINE, Sylvie (1993): «Une image des cités de Bétique aux $\mathrm{II}^{\mathrm{e}}$ et $\mathrm{II}^{\mathrm{e}}$ siècles après J.-C.: l'emploi du terme respublica dans les inscriptions de la province», Ciudad y Comunidad Cívica en Hispania (Siglos II y III d. C.), Madrid, 46-58.

DESSAU, Hermannus (1974): Inscriptiones latinae selectae, vol. II, pars II, Dublin/ /Zurique.

ENCARNAÇÃO, José (1984a): «Reflexões sobre a epigrafia de Ossonoba», Conimbriga, 23, 5-18.

EnCARnaÇão, José (1984b): Inscrições Romanas do Conventus Pacensis, Coimbra. ENCARNAÇÃO, José (1990): «Religião e cultura na epigrafia de Liberalitas Iulia (Subsídios para o seu estudo)», Les Villes de Lusitanie Romaine, Paris, 233-253.

EnCARnAÇÃo, José; MonteIRO, António J. Nunes (1993-1994): «A propósito de uma inscrição latina em Santiago da Guarda (Ansião)», Conimbriga, 32-33, 303-311. ÉtIENNE, Robert; FABRE, Georges (1976): «Épigraphie», in Fouilles de Conimbriga, vol. II, Paris, 13-232.

ÉtIENNE, Robert; MAYET, Françoise (1984): «La dénomination antique de Mérida», in Homenagem a D. Domingos de Pinho Brandão, Lucerna, Porto, 159-172. FERnANDES, Luís da Silva (1997): «Inscrições romanas de Tomar e seu termo», Boletim Cultural da Câmara Municipal de Tomar, . $^{\circ} 21$, Outubro, 149-213.

FERNANDES, Luís da Silva (1998): «Peso de tear epigrafado de Tomar (conuentus Scallabitanus)», Ficheiro Epigráfico, 59, n. ${ }^{\circ} 274$.

FERnANDES, Luís da Silva (1998-99): «A Presença da Mulher na Epigrafia Romana do Conventus Scallabitanus», Portugália, XIX-XX, 129-228.

FERreIRA, Rui; PonTE, Salete da (1992): «A villa suburbana de Cardais, Tomar - sua história», O Espaço Rural na Lusitânia. Tomar e o Seu Território (Actas do Seminário, Tomar, 17 a 19 de Março, 1989), Tomar, 55-57.

GASCOU, Jacques (1979): «L'emploi du terme Respublica dans l'épigraphie latine d'Afrique», Mélanges de l'École Française de Rome, 91, 383-398. 
GonzÁlez RodríGuez, M. - Cruz (1994): «Apuntes sobre religion y ciudad en la Betica: a proposito de una inscripcion de la Res Publica Reginensium (Casas de Reina, Badajoz)», III Congreso Peninsular de Historia Antigua - Preactas, Vitoria, Julio, vol. II, 682-690.

LE RouX, Patrick (1990): «Les villes de statut municipal en Lusitanie romaine», Les Villes de Lusitanie Romaine, Paris, 35-49.

LE RouX, Patrick (1994): «La questione municipale nel I secolo d. C. l'esempio spagnolo», Epigrafia e territorio. Politica e società. Temi di antichità romane III, Bari, 159-173.

Mantas, Vasco (1992): «Vias romanas da região de Tomar: os marcos miliários», O Espaço Rural na Lusitânia. Tomar e o Seu Território (Actas do Seminário, Tomar, 17 a 19 de Março, 1989), Tomar, 31-46.

MARICHAL, Robert (1988): Les Graffites de la Graufesenque, Paris.

Ors, A.; Ors, Javier d' (1988): Lex Irnitana, in Cadernos Compostelanos de Derecho Romano, n. ${ }^{\circ}$, Universidad de Santiago de Compostela.

PONTE, Salete da (1985): «Tomar: história e geografia humanas no tempo e no espaço», Arqueologia na Região de Tomar (da Pré-história à actualidade), suplemento do Boletim Cultural e Informativo da Câmara Municipal de Tomar, n. ${ }^{\circ} 1,13-25$.

Ponte, Salete da (1988): Villa rústica de S. Pedro de Caldelas - Tomar, Centro de Estudos de Arte e Arqueologia, n. ${ }^{\circ}$ 1, Tomar.

PONTE, Salete da (1993): «Achegas sobre a estrutura urbana de Sellium (Tomar)», Actas del XXII Congreso Nacional de Arqueología, vol. II, Vigo, 447-459.

Ponte, Salete da (1996): «Um forno romano (?) em Assentiz», Almadan, II. ${ }^{a}$ Série, n. ${ }^{\circ} 5$, Outubro, 199.

Ponte, Salete da; FernANDES, Luís (1993): «Sellium romana: sua história», Boletim Cultural da Câmara Municipal de Tomar, n. ${ }^{\circ}$ 19, Outubro, 161-189.

Rico, Christian (1993): «Production des matériaux de terre cuite en Tarraconaise», Mélanges de la Casa de Velázquez, XXIX (1), 51-86.

RóldAN GómEZ, Lourdes (1993): «El estudio y la valoración de las técnicas constructivas romanas en la Península Ibérica. Analisis historiográfico», Actas do $1 .^{\circ}$ Congresso de Arqueologia Peninsular (Porto, 12-18 de Outubro de 1993), vol. I, in Trabalhos de Antropologia e Etnologia, vol. XXXIII (fasc. 1-2), Porto, 329-350.

SILVA, Eugénio Sobreiro de Figueiredo e (1951): «Escavações arqueológicas no cerrado de João do Couto em Tomar», Actas da União dos Amigos dos Monumentos da Ordem de Cristo, vol. III, Tomar, 44-52.

SILVA, Joaquim Possidónio N. da, (1883): «Descobrimento da cidade romana "Nabancia” em Portugal», Boletim da Real Associação dos Architectos Civis e Archeologos Portugueses, série II, tomo 3 (10), 152-154.

SILVA, Victor (1985): «Algumas achegas para o estudo da ocupação romana na região de Tomar», Arqueologia na Região de Tomar (da Pré-história à actualidade), suplemento do Boletim Cultural e Informativo da Câmara Municipal de Tomar, n. ${ }^{\circ} 1,131-137$. 
S. FERNANDES, R. FERREIRA, Marcas de oficina em tijolos romanos de Seilivm 267

Tsiolis, Vasilis G. (1997): «Las restrictions de la producción tegularia en la Lex Ursonensis», La Lex Ursonensis, in Studia Historica (Historia Antigua), 15, 1997, 119-136.

WAHL, J. (1988): «Três Minas. Vorbericht über die archäologischen Untersuchungen im Bereich des römischen Goldbergwerks 1986-1987», Madrider Mitteilungen, 29, 221-244.

Veloso, Carlos (1992): «Garcês Teixeira - o historiador», Boletim Cultural da Câmara Municipal de Tomar, $\mathrm{n} .{ }^{\circ}$ 16, Março, 151-168. 

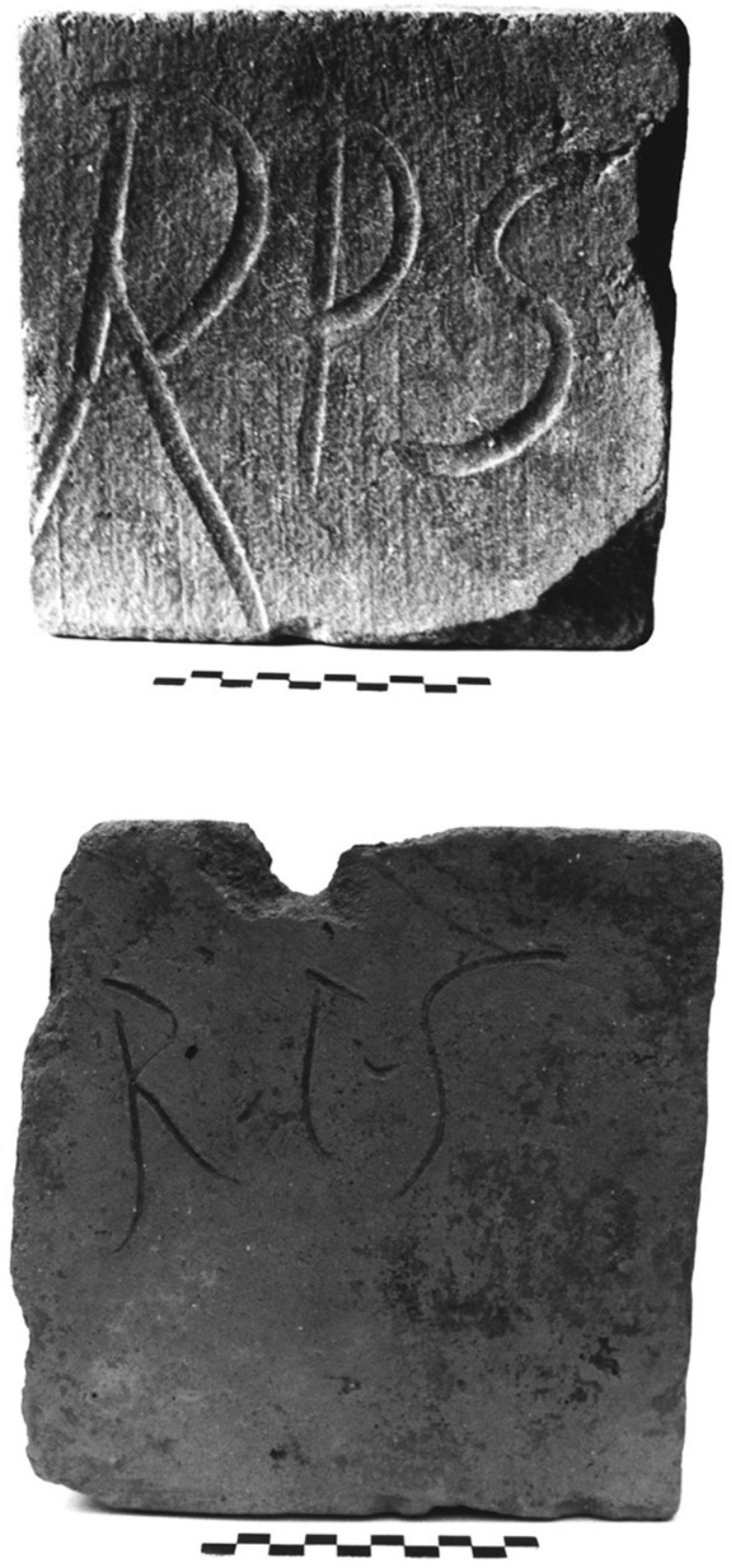

EsT. I 